\title{
Comparing the Reaction Rates of Plasmonic (Gold) and Non- Plasmonic (Palladium) Metal Particles in Photocatalytic Hydrogen Production
}

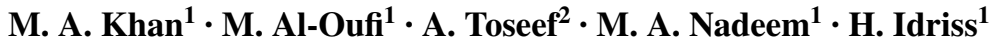

Received: 24 June 2017 / Accepted: 15 September 2017 / Published online: 11 October 2017

(C) The Author(s) 2017. This article is an open access publication

\begin{abstract}
Both Pd and Au metal particles are used in photocatalytic hydrogen generation. Yet while both act as electron sink only gold is poised to respond to visible light due to its plasmonic response. In order to quantitatively gauge their relative contribution into the reaction, the photocatalytic $\mathrm{H}_{2}$ production, from $\mathrm{Au} / \mathrm{TiO}_{2}$ and $\mathrm{Pd} / \mathrm{TiO}_{2}$ catalysts was studied under UV and UV-Vis light. While under UV light excitation, a weak dependence on the work function of the metal is observed, under UV-Vis light, Au is found to be twice more active than Pd. Under identical UV-Vis light irradiation, the turn over frequency calculated from XPS at.\% is found to be 2.8 and $1.8 \mathrm{~s}^{-1}$ for $\mathrm{Au}$ and $\mathrm{Pd}$, respectively. The effect is far more pronounced when the rates are normalized to the number of particles of each metal. Both the semiconductor $\mathrm{TiO}_{2}$ (UV light) and the plasmonic metal (visible light) need to be excited for the enhancement to occur; visible light alone causes a negligible reaction rate. Photocurrent measurements further confirmed the difference in the photocatalytic activity under UV and UV-Vis light excitation. Moreover, because of the presence of Au particles responding to visible light the reaction rate is enhanced due to "light penetration depth" effect.
\end{abstract}

H. Idriss

IdrissH@SABIC.com

1 SABIC Corporate Research and Development (CRD), KAUST, Thuwal, Saudi Arabia

2 SABIC Technology and Innovation Center, Riyadh, Saudi Arabia

\section{Graphical Abstract}

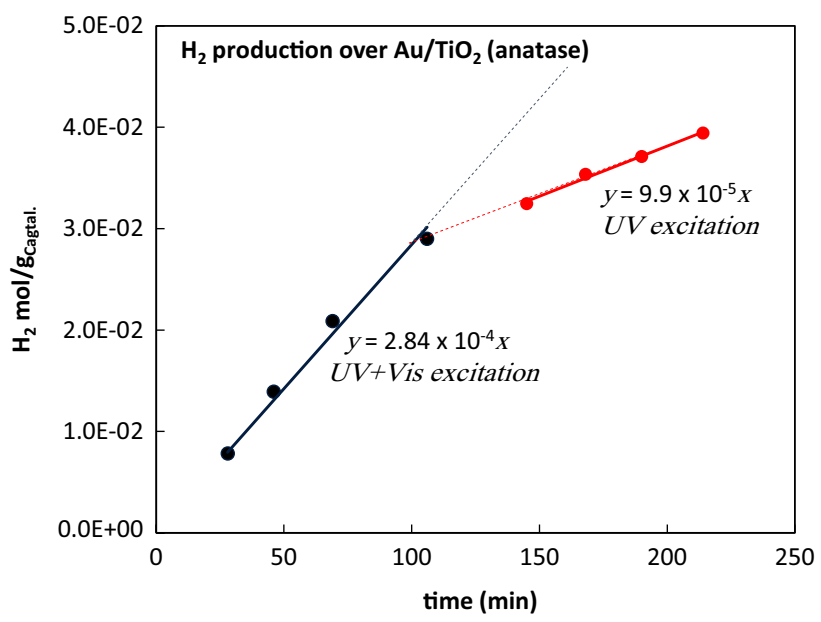

Keywords Photocatalysis - Hydrogen production · Plasmon $\cdot \mathrm{Au} / \mathrm{TiO}_{2} \cdot$ Metal particle size $\cdot$ Reaction rate

\section{Introduction}

Photocatalytic hydrogen production from renewables is a promising route for future economies to replace fossil fuels for transportation and chemical manufacturing. The development of an active, scalable and stable photocatalyst remains one of the biggest challenges in modern day catalysis. Many families of semiconductors have been made and tested including oxide semiconductors such as $\mathrm{TiO}_{2}$, $\mathrm{ZnO}, \mathrm{WO}_{3}, \mathrm{BiVO}_{4}$, [1-4] sulfide semiconductors such as $\mathrm{CdS}, \mathrm{ZnS}, \mathrm{Mo}_{\mathrm{x}} \mathrm{S}_{\mathrm{y}}$, [5-7] and nitride semiconductors such as $\mathrm{GaN}$, InGaN, $\mathrm{C}_{3} \mathrm{~N}_{4}$ [8-10]. These semiconductors alone or in mixed forms including solid solutions and abrupt interfaced materials such as layer by layer growth or layer 
plus island growth, have not, yet, provided the needed activity nor stability [11-14]. $\mathrm{TiO}_{2}$ is widely regarded as one of the leading candidates for solar hydrogen production because of its excellent stability. Nonetheless, $\mathrm{TiO}_{2}$ suffers from low solar to hydrogen conversion efficiency because of high charge carrier recombination rates and limited light absorption $(<400 \mathrm{~nm})$ [15]. Loading of noble metal nanoparticles such as $\mathrm{Pt}, \mathrm{Pd}$ and $\mathrm{Rh}$ on $\mathrm{TiO}_{2}$ is needed to improve its photocatalytic efficiency $[15,16]$. The role of noble metal particles, their particle size and dispersion effect has been studied by us and others for a while [4, 17-24]. Their role is, so far, understood as an electron sink to reduce charge carrier recombination rate and therefore increase $\mathrm{H}^{+}$reduction (a much slower process) to molecular hydrogen.

Over the past decade, the roles of plasmonic metal nanoparticles such as Au and Ag have come into focus as a promising technology for further improving light absorption and charge generation at the semiconductor interface [25]. These metals absorb visible light and are reported to enhance the photocatalytic activity of semiconductors $[26,27]$. In that regard, $\mathrm{Au} / \mathrm{TiO}_{2}$ photocatalysts have been studied in various forms such as nanoparticles, core shell structures and thin films to unravel the major mechanisms involved in plasmonic photocatalysis and to provide physical explanations for enhanced activities [28-30]. In light of the many reports in literature, questions remain on the differences between the role of non-plasmonic metal, the role of plasmonic metal and ultimately what would be the best metal combination for synthesizing a practical catalyst? Due to differences in reaction, conditions conducted by different groups a clear comparison between the role of non-plasmonic metal and a plasmonic metal is not available. Differences such as BET surface area, degree of crystallinity, semiconductor crystallite size, catalyst loading inside the reactor (which affect light absorption), reactor design, can considerably affect the rates and may lead to non-conclusive results.

In this study, we have investigated the photocatalytic $\mathrm{H}_{2}$ production activity of anatase $\mathrm{TiO}_{2}$ upon loading plasmonic $(\mathrm{Au})$ and non-plasmonic metal (Pd) nanoparticles at $0.3 \mathrm{wt} \%$. We have characterized the photo-catalysts using UV-Vis absorption, BET, XPS and TEM. The powdered catalysts were coated onto glass slides and the $\mathrm{H}_{2}$ production activity and photocurrent response were measured in $5 \mathrm{vol} \%$ glycerol aqueous solutions under identical light flux. For the catalytic reaction conducted at identical conditions, we have extracted the intrinsic rates and compared them. Results indicate that indeed Au plasmon increases the reaction rate for hydrogen ions reduction under visible light and consequently allows for increasing the light penetration depth.

\section{Experimental}

\subsection{Catalysts Preparation}

Anatase $\mathrm{TiO}_{2}$ (commercial Hombikat UV 100 produced by Huntsman - formerly Sachtleben Chemie) with an average particle size of $\sim 7 \mathrm{~nm}$ (measured using TEM) and initial BET surface area $\sim 320 \mathrm{~m}^{2} / \mathrm{g}$ was impregnated with the required amount of $\mathrm{PdCl}_{2}$ (in $1.87 \mathrm{M} \mathrm{HCl}$ ) or $\mathrm{HAuCl}_{4}$ salt solutions $\left(0.2 \mathrm{M}_{\text {in }} \mathrm{H}_{2} \mathrm{O}\right)$. The mixture was dried by evaporating excess water under constant stirring with slow heating at $80{ }^{\circ} \mathrm{C}$. The dried catalysts were calcined at $400{ }^{\circ} \mathrm{C}$ for $4 \mathrm{~h}$. The resulting catalysts had an average particle size of $\sim 10-12 \mathrm{~nm}$ (TEM) and a BET surface area of $\sim 112 \mathrm{~m}^{2} / \mathrm{g}$. Microscopic glass slides were cleaned by ultra-sonication in acetone, ethanol and then DI water. The powder catalysts were dispersed in absolute ethanol (5 wt $\%$ dispersion) and spun coated onto the glass at $500 \mathrm{rpm}$ for $20 \mathrm{~s}$. The coatings were dried at $100{ }^{\circ} \mathrm{C}$ for $20 \mathrm{~min}$ before testing.

\subsection{Catalysts Characterization}

UV-Vis absorbance spectra of the powdered catalysts were collected over the wavelength range of $250-900 \mathrm{~nm}$ on a Thermo Fisher Scientific spectrophotometer equipped with praying mantis diffuse reflectance accessory. Absorbance (A) and reflectance (\% R) of the samples were recorded. The reflectance $(\% \mathrm{R})$ data was used to calculate the band gap of the samples using the Tauc plot (Kubelka-Munk function). The Kubelka-Munk method is generally used for the analysis of diffuse reflectance spectra obtained from weakly absorbing samples. It provides a correlation between reflectance and concentration. The concentration of an absorbing species can be determined using the Kubelka Munk formula: $\mathrm{F}(\mathrm{R})=(1-\mathrm{R})^{2} / 2 \mathrm{R}=\mathrm{k} / \mathrm{s}=\mathrm{Ac} / \mathrm{s}$, where $\mathrm{R}$ is reflectance, $\mathrm{k}$ is absorption coefficient, $\mathrm{s}$ is scattering coefficient, $\mathrm{c}$ is concentration of the absorbing species and $\mathrm{A}$ is the absorbance. The optical band gap of semiconductors can be determined by plotting $(F(R) \times E)^{1 / r}$ against the radiation energy in $(e V)$, using $r=2$ for indirect allowed transitions of charge carriers (indirect band gap material) or $r=1 / 2$ for direct allowed transition (direct band gap material). The resulting plot has a distinct linear regime, which denotes the onset of absorption. Thus, extrapolating this linear region to the abscissa yields the energy of the optical band gap of the material.

XPS was conducted using a Thermo scientific ESCALAB $250 \mathrm{Xi}$. The samples were prepared by attaching the powdered catalyst particles in the form of thick layer to standard XPS sample carrier block using $10 \mathrm{~mm}$ diameter carbon tabs. The base pressure of the chamber was typically in the low $10^{-9}$ to high $10^{-10}$ mbar range. $\mathrm{Al} \mathrm{K \alpha} \mathrm{X}$-ray was used with a spot size of $650 \mu \mathrm{m}^{2}$. Charge neutralization was used for all samples $(1 \mathrm{eV})$. Spectra were calibrated with respect 
to $\mathrm{C} 1 \mathrm{~s}$ at $285.0 \mathrm{eV}$. Quantitative analyses were conducted using the following sensitivity factors with respect to F1s (1): Ti2 $\mathrm{p}_{3 / 2}$ (1.1), O1s (0.63), C1s (0.21) Au4f $\mathrm{f}_{7 / 2}$ (1.9) and $\operatorname{Pd} 3 d_{5 / 2}(2)$.

Transmission electron microscopy analysis of samples was performed with a Titan 80-300 ST microscope from FEI Company (Hillsboro, OR). The microscope was set to the operating voltage of $300 \mathrm{kV}$ and scanning TEM (STEM) mode during the analysis. Furthermore, STEM signal was collected with a high-angle annular dark-field detector in the range of 75-200 mard to enhance atomic number (Z) contrast. In this way, STEM images were acquired at various image magnifications.

\subsection{Catalysts Tests}

Photocatalytic reactions were evaluated in a $145 \mathrm{~mL}$ volume Quartz glass reactor. $30 \mathrm{~mL}$ of $5 \mathrm{vol} \%$ glycerol aqueous solution was used and the reactor was purged with $\mathrm{N}_{2}$ gas for 15 min to remove any $\mathrm{O}_{2}$ prior to start the reaction. Photoreactions were carried out under UV light and UV-Vis light using a mercury lamp and Xenon lamp, respectively. The light flux was measured with a spectro-radiometer (Spectral Evolution SR-500). The total flux from the mercury lamp at $365 \mathrm{~nm}$ was $\sim 7.62 \mathrm{~mW} / \mathrm{cm}^{2}$ while total flux from Xenon lamp was $~ 219 \mathrm{~mW} / \mathrm{cm}^{2} \mathrm{UV}\left(320-400 \mathrm{~nm}-8.6 \mathrm{~mW} / \mathrm{cm}^{2}\right)$ and visible $\left(400-620 \mathrm{~nm}-211 \mathrm{~mW} / \mathrm{cm}^{2}\right)$. Products monitoring was performed by gas chromatograph equipped with thermal conductivity detector connected to Porapak Q packed column ( $2 \mathrm{~m}$ long, $1 / 8 \mathrm{in}$. external diameter) at $45^{\circ} \mathrm{C}$ and $\mathrm{N}_{2}$ was used as a carrier gas (flow rate of $20 \mathrm{~mL} / \mathrm{min}$ ) at 8 psi. The reaction under UV light was carried out first then after the experiment the reactor was purged again and reaction was carried out under UV-Vis light. The short circuit photocurrents were measured using a two electrode setup under zero bias and from $5 \mathrm{vol} \%$ glycerol (in $1 \mathrm{M} \mathrm{NaOH}$ ) solution. Working electrode consisted of the $\mathrm{M} / \mathrm{TiO}_{2}$ photocatalysts coated on ITO/glass electrodes $\left(4 \mathrm{~cm}^{2}\right.$ area) with $\mathrm{Pt}$ as counter electrode.

\section{Results and Discussion}

Figure 1a shows the UV-Vis absorption spectra for the $\mathrm{M} / \mathrm{TiO}_{2}$ photocatalysts measured using diffuse reflectance spectroscopy. Spectra show typical absorption from anatase $\mathrm{TiO}_{2}$ with a band edge around $370-380 \mathrm{~nm}\left(\mathrm{E}_{\mathrm{g}} \sim 3.2 \mathrm{eV}\right)$ due to the charge-transfer from the valence band formed by $\mathrm{O} 2 \mathrm{p}$ orbitals to the conduction band formed by $\mathrm{Ti}^{4+} 3 \mathrm{~d}$ $\mathrm{t}_{2 \mathrm{~g}}$ orbitals. The $\mathrm{Au} / \mathrm{TiO}_{2}$ catalyst displayed a broad absorption feature centered at $560 \mathrm{~nm}$ due to the localized surface plasmon resonance (LSPR) of the Au nanoparticles on top of the semiconductor $\mathrm{TiO}_{2}$. On the other hand, $\mathrm{Pd} / \mathrm{TiO}_{2}$ does not show a discrete surface plasmon absorption in the visible spectrum because of a damping effect caused by $d-d$ interband transitions (i.e. the plasmon energy is lost by excitation of single electron interband transitions) [31, 32]. For $\mathrm{Pd} / \mathrm{TiO}_{2}$, the absorption peak centred at about $470 \mathrm{~nm}$ can be ascribed to electron transition from the energy level of -O-Pd-O- surface species to the conduction band of $\mathrm{TiO}_{2}$ [33]. Tauc plots are shown in Fig. $1 \mathrm{~b}(\mathrm{r}=2)$ for $\mathrm{TiO}_{2}$ and $\mathrm{M} /$ $\mathrm{TiO}_{2}$; giving a gap of $\sim 3.2 \mathrm{eV}$.

XPS analysis was conducted on the $\mathrm{M} / \mathrm{TiO}_{2}$ photocatalysts to determine the metal amount on the surface of the catalysts. Figure 1c presents XPS Au4f where Au presence is seen by the peaks centered at 84.3 and 88.0 attributed to $A u 4 f_{7 / 2}$ and $A u 4 f_{5 / 2}$, respectively. The peak positions, spin-orbit splitting (SOS) of $3.7 \mathrm{eV}$ and FWHM $\left(\mathrm{Au} 4 \mathrm{f}_{7 / 2}=0.7 \mathrm{eV} ; \mathrm{Au} 4 \mathrm{f}_{5 / 2}=0.7\right)$ are characteristic of metallic gold [34]. In the case of $\mathrm{Pd} / \mathrm{TiO}_{2}$ (Fig. 1d), two $\mathrm{Pd} 3 \mathrm{~d}_{5 / 2}$ peaks at 335 and $336.5 \mathrm{eV}$ typical for $\mathrm{Pd}$ metal and $\mathrm{PdO}$ can be observed, respectively. The total at.\% were found to be equal to $0.13 \%$ for $\mathrm{Pd}$ and $0.08 \%$ for Au, respectively as listed in Table 1. Figure 1e, f show STEM images of the $\mathrm{Au} / \mathrm{TiO}_{2}$ and $\mathrm{Pd} / \mathrm{TiO}_{2}$ photocatalysts. Au particle density is less than that of Pd, which is due to its larger size. Although complete statistical counting was not possible because of the low loading we have estimated the mean particle size of $\mathrm{Au}$ and Pd to be $\sim 3$ and $\sim 1 \mathrm{~nm}$, respectively.

The $\mathrm{H}_{2}$ production activities were tested using 5 vol\% aqueous glycerol solutions under identical light flux and amount of catalyst to rule out the effects of scattering, reflection and light penetration depth. The reaction rates were stable and reproducible, typical of these type of catalysts (parallel catalytic tests have shown constant reaction rates on these catalysts for periods of months as long as the amount of sacrificial agent is kept constant) [35]. Figure 2a shows the $\mathrm{H}_{2}$ production rates under UV excitation. Pure $\mathrm{TiO}_{2}$ (without metal) does not give significant amount of hydrogen over a period of $4 \mathrm{~h}$. The photocatalytic activity increases by ca. two orders of magnitude when $0.3 \mathrm{wt} \%$ of a metal is present. The role of metal loading in photocatalysis is still not well understood since unlike thermal catalytic reactions there is a very narrow window of concentration where it works best (typically between 0.1 and $1 \mathrm{wt} \%$ ). The $\mathrm{H}_{2}$ production rates under UV light was different for both metals (at identical conditions). $\mathrm{Pd} / \mathrm{TiO}_{2}$ catalyst was more active than $\mathrm{Au} / \mathrm{TiO}_{2}$ when the rates are normalized to the total amount of catalyst or to the total amount of metal (Fig. 2a, b). This may be due to differences in the work function (WF) of $\mathrm{Pd}(5.6 \mathrm{eV}), \mathrm{Au}$ $(5.3 \mathrm{eV})$ with respect to $\mathrm{TiO}_{2}(4.2 \mathrm{eV})[19,36]$. If the role of the metal particle is as an electron sink, the $\mathrm{H}_{2}$ production rates should depend on/relate to the WF of the metal. Yet the WF also changes with the metal particle size and this can affect the results differently. In general, the WF 
Fig. 1 a UV-Vis absorption spectra of $\mathrm{M} / \mathrm{TiO}_{2}$ photocatalysts, b Plots of Tauc units versus (eV) for the same series, c $\mathrm{Au}$ 4f XPS spectrum of $\mathrm{Au} /$ $\mathrm{TiO}_{2}$ and $\mathbf{d} \mathrm{Pd} 3 \mathrm{~d}$ XPS spectrum of $\mathrm{Pd} / \mathrm{TiO}_{2}$, e STEM image of $0.3 \mathrm{wt} \% \mathrm{Au} / \mathrm{TiO}_{2}$, f STEM image of $0.3 \mathrm{wt} \% \mathrm{Pd} / \mathrm{TiO}_{2}$

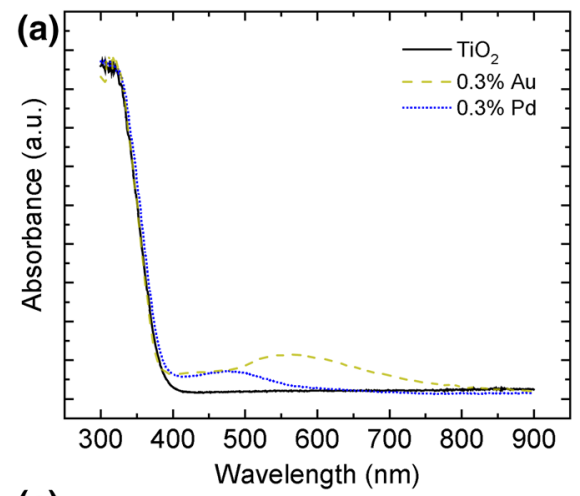

(c)

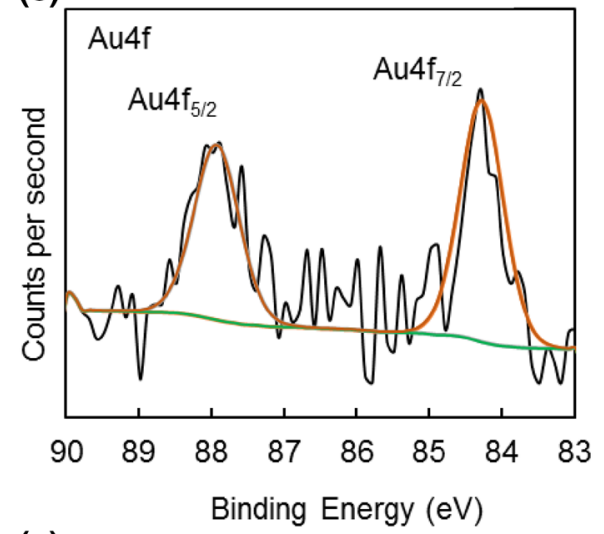

(e)

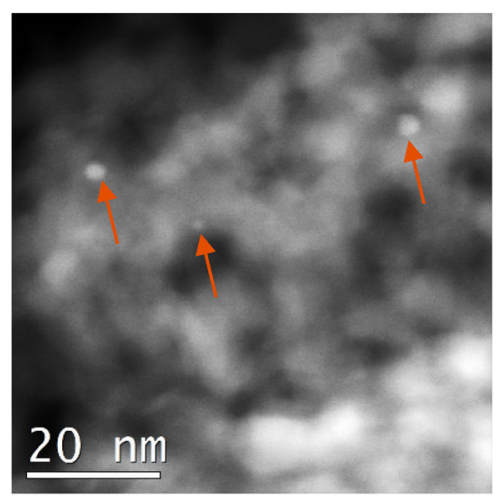

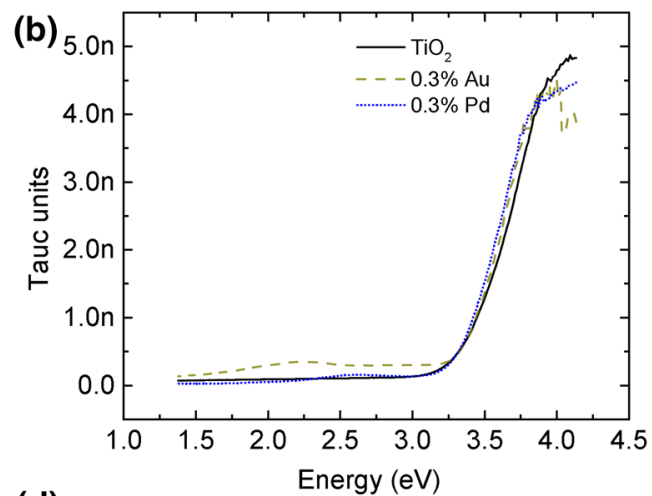

(d)

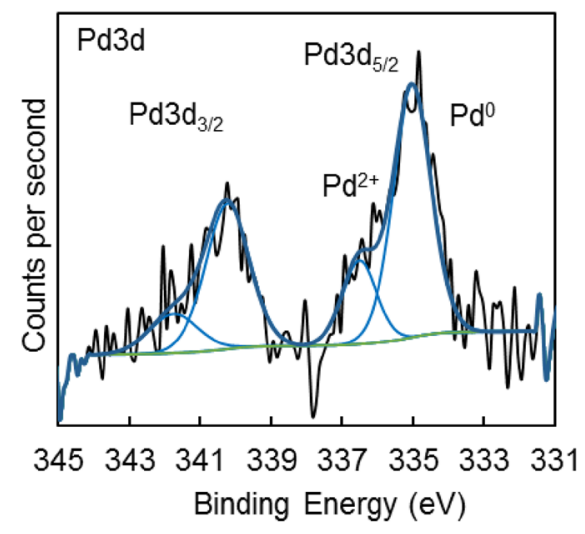

(f)

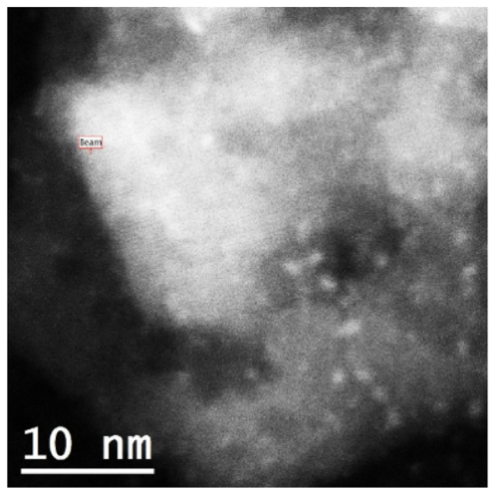

Table 1 XPS analysis with binding energy peak position, full width half maxima, spin orbital splitting and atomic concentration

\begin{tabular}{llllll}
\hline $\begin{array}{l}\text { Chemical } \\
\text { composition }\end{array}$ & Core level & $\begin{array}{l}\text { Peak posi- } \\
\text { tion }(\mathrm{eV})\end{array}$ & FWHM (eV) & SOS & at.\% \\
\hline $\mathrm{Pd}$ & ${\mathrm{Pd} 3 \mathrm{~d}_{5 / 2}}$ & 335 & 1.2 & 5.2 & 0.09 \\
& ${\mathrm{Pd} 3 \mathrm{~d}_{3 / 2}}_{4} \mathrm{PdO}$ & 340.2 & 1.5 & & \\
& $\mathrm{Pd} 3 \mathrm{~d}_{5 / 2}$ & 336.5 & 1.2 & 5.3 & 0.04 \\
$\mathrm{Au}$ & ${\mathrm{Pd} 3 \mathrm{~d}_{3 / 2}}_{4}$ & 341.8 & 1.6 & & \\
& $\mathrm{Au} 4 \mathrm{f}_{7 / 2}$ & 84.3 & 0.7 & 3.7 & 0.08 \\
& $\mathrm{Au}_{5 / 2}$ & 88.0 & 0.7 & & \\
\hline
\end{tabular}

increases with decreasing particle size so that may slightly be in favor of the same argument since Pd particles are much smaller than Au particles.

$\mathrm{H}_{2}$ rates per metal particle indicate that $\mathrm{Au}$ particles show, however, an order of magnitude more activity than Pd particles (Fig. 2c). This is in sharp contrast to thermal catalytic reactions in general, where reaction rates usually correlate with active metal surface area and higher dispersion generally gives higher reaction rates. This result is similar to pervious study by our group comparing $\mathrm{Pd}, \mathrm{Pt}$, and $\mathrm{Au}$ on $\mathrm{TiO}_{2} \mathrm{P} 25$ [19]. If we consider the number of atoms in each particle (i.e. the rate per particle divided by the number of atoms in each particle), the $\mathrm{H}_{2}$ production rates are almost identical (Fig. 2d). 
Fig. 2 Rates of $\mathrm{H}_{2}$ production for the $\mathrm{M} / \mathrm{TiO}_{2}$ catalysts from 5 vol\% glycerol solutions under UV light (365 nm, $7.6 \mathrm{~mW} /$ $\mathrm{cm}^{2}$ ); Reactor volume: $145 \mathrm{~mL}$; Area of coating: $4 \mathrm{~cm}^{2} ; 0.4 \mathrm{mg}$ catalyst a mass normalized rates, $\mathbf{b}$ metal mass normalized rates, $\mathbf{c}$ rates per metal particle and $\mathbf{d}$ rates/total metal atoms in each particle
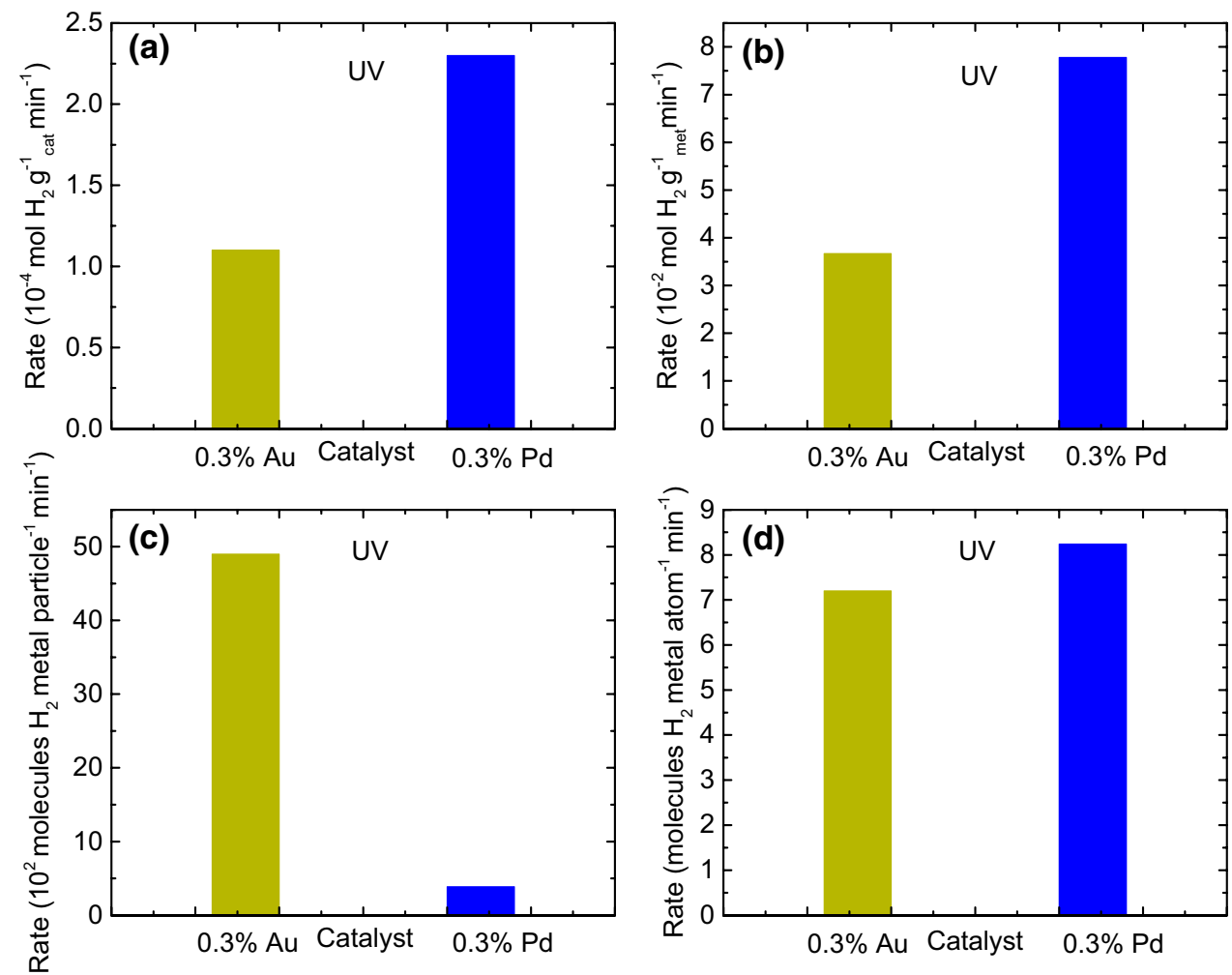

Therefore, form this set of data we can say the three following observations when the catalyst is excited with UV light.

(i) The rate of hydrogen production is higher for Pd than Au based on mass,

(ii) It is higher for Au than Pd based on particles number and

(iii) It is very similar based on the number of metal atoms.

Next, we have tested the $\mathrm{H}_{2}$ production activities of these photo-catalysts under identical UV-Vis light fluxes. Figure $3 \mathrm{a}, \mathrm{b}$ show the $\mathrm{H}_{2}$ production rates normalized to the weight of catalyst as well as that of metals. While the $\mathrm{Pd}$ / $\mathrm{TiO}_{2}$ catalyst showed similar activity as under pure UV light, $\mathrm{Au} / \mathrm{TiO}_{2}$ displayed a two-fold increase versus its activity under pure UV light. If we calculate $\mathrm{H}_{2}$ production rates per metal particle, it is ca. 25 times per Au particle higher than per Pd particle (Fig. 3c). Equally important $\mathrm{H}_{2}$ production rates per $\mathrm{Au}$ atom are larger (ca. two times) than that per Pd atom (Fig. 3d). The second column of Table 2 contains the XPS corrected at.\% of Au and Pd. Due to the small size of metal particles (up to ca. $3 \mathrm{~nm}$ ) all metal atoms are quantified because the escape depth of the photoelectrons excited by $\mathrm{Al} \mathrm{K}_{\alpha}$ line (about $2 \mathrm{~nm}$, which makes it possible to account for particles with diameter up to about $4 \mathrm{~nm}$ ). In other words, when compared to UV light, excitation with $\mathrm{UV}-\mathrm{Vis}$ resulted in reaction rate that are (i) Similar for Pd and Au per mass

(ii) Negligible for Pd when compared to Au per particle

(iii) Lower for Pd when compared to Au per atom.

This result is different from our earlier reports on $\mathrm{M} /$ $\mathrm{TiO}_{2}$ systems, where the catalysts where tested under only UV light [17, 19]. This difference can be linked in part to plasmonic effect of $\mathrm{Au}$; responding under visible light irradiation. Further data analysis is provided upon normalization of the reaction rates by the light flux (Fig. 4), $\mathrm{Au} / \mathrm{TiO}_{2}$ now performs (per unit mass) as good as $\mathrm{Pd} / \mathrm{TiO}_{2}$. Lastly, we also carried out photoreactions under pure visible light (400-630 nm) but only traces of hydrogen could be detected. This suggests that Au nanoparticles alone cannot make the $\mathrm{H}^{+}$ions reduction to molecular hydrogen i.e. both the semiconductor $\left(\mathrm{TiO}_{2}\right)$ and the plasmonic metal $(\mathrm{Au})$ need to be excited to see an enhancement in $\mathrm{H}_{2}$ production rates. Another important point to extract from this result is that increasing particle density does not translate into increasing reaction rate, even though the reaction occurs at the interface metal/semiconductor.

To further investigate the contribution of Au in improving the photocatalytic activity we measured the short-circuit photocurrents under zero applied bias voltage for the different catalysts. Exact amounts of catalysts were coated onto ITO/glass substrates. The electrolyte used was $1 \mathrm{M} \mathrm{NaOH}$ with 5 vol\% glycerol and a Pt wire was used as the counter electrode. Figure 5a presents the photocurrent measured 
Fig. 3 Rates of $\mathrm{H}_{2}$ production for the $\mathrm{M} / \mathrm{TiO}_{2}$ photocatalysts from $5 \mathrm{vol} \%$ glycerol solutions under UV flux (300-400 nm): $8.6 \mathrm{~mW} / \mathrm{cm}^{2}$ and visible flux $(400-700 \mathrm{~nm}): 75 \mathrm{~mW} / \mathrm{cm}^{2} \mathbf{a}$ photocatalyst mass normalized rates, b metal co-catalyst mass normalized, $\mathbf{c}$ rates per metal particle and $\mathbf{d}$ rates/total metal atoms in each particle
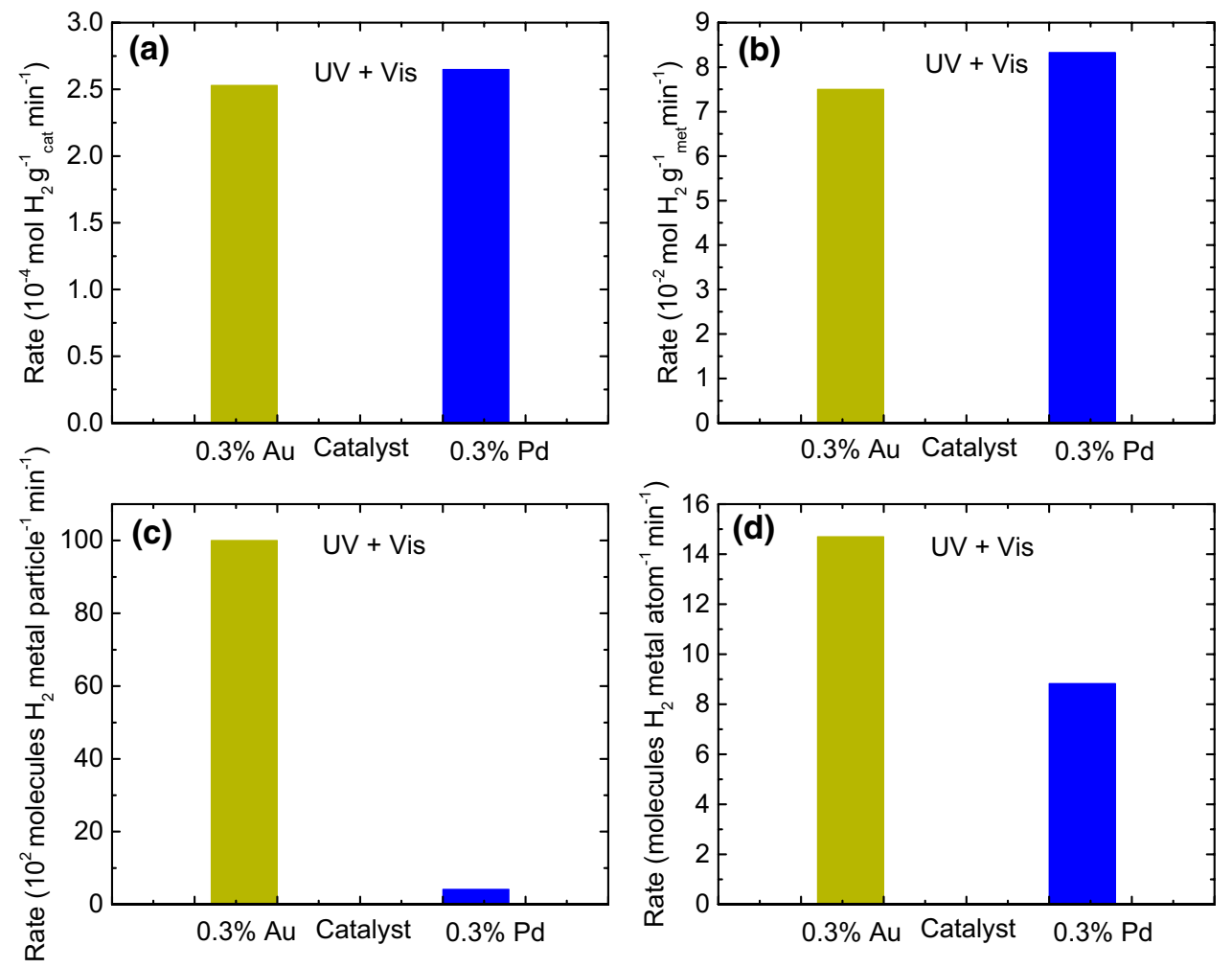

Table 2 Photocatalytic production of $\mathrm{H}_{2}$ over the $\mathrm{Au} / \mathrm{TiO}_{2}$ and $\mathrm{Pd} / \mathrm{TiO}_{2}$ under $\mathrm{UV}$ and $\mathrm{UV}-\mathrm{Vis}$ irradiation with rates normalized to $\mathrm{BET}$ surface area and turn over frequency (TOF) $\left(\mathrm{s}^{-1}\right)$

\begin{tabular}{llllll}
\hline Catalyst & $\begin{array}{l}\text { Metal at.\% } \\
\text { (XPS) }\end{array}$ & $\begin{array}{l}\text { Rate normalized to surface } \\
\text { area- }-\mathrm{mol} / \mathrm{min} / \mathrm{m}^{2}(\mathrm{UV})\end{array}$ & $\begin{array}{l}\text { Turn over fre- } \\
\text { quency }\left(\mathrm{s}^{-1}\right)\end{array}$ & $\begin{array}{l}\text { Rate normalized to surface area- } \\
\mathrm{mol} / \mathrm{min} / \mathrm{m}^{2}(\mathrm{UV}-\mathrm{Vis})\end{array}$ & $\begin{array}{l}\text { Turn over } \\
\text { frequency } \\
\left(\mathrm{s}^{-1}\right)\end{array}$ \\
\hline $0.3 \% \mathrm{Au} / \mathrm{TiO}_{2}$ & 0.08 & $9.8 \times 10^{-7}$ & 1.2 & $2.3 \times 10^{-6}$ & 2.8 \\
$0.3 \% \mathrm{Pd} / \mathrm{TiO}_{2}$ & 0.13 & $2.1 \times 10^{-6}$ & 1.6 & $2.4 \times 10^{-6}$ & 1.8 \\
\hline
\end{tabular}

BET surface area for both catalysts was $\sim 112 \mathrm{~m}^{2} / \mathrm{g}$. TOF was calculated by taking the at. $\%$ of the metal from XPS and the fact that $1 \mathrm{~m}^{2}$ contains about $10^{19}$ atoms

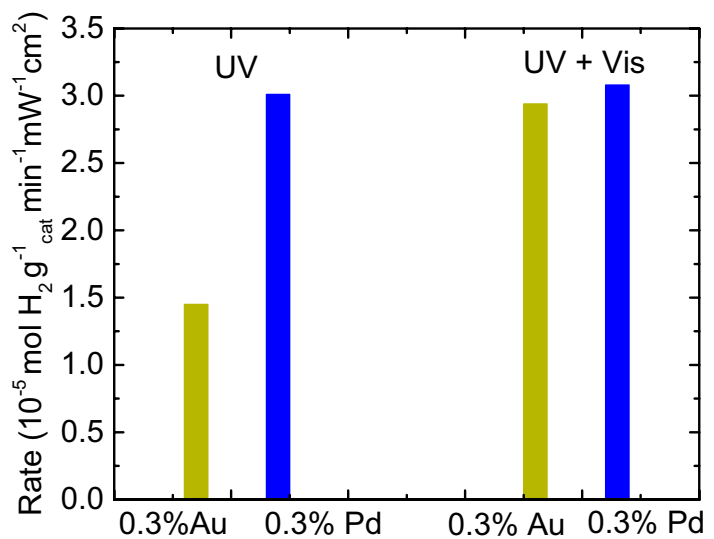

Fig. 4 Hydrogen production rates ( $\mathrm{mol} / \mathrm{g} / \mathrm{min})$ normalized to UV light flux $\left(7.6 \mathrm{~mW} / \mathrm{cm}^{2}\right.$ in UV and $8.6 \mathrm{~mW} / \mathrm{cm}^{2}$ under UV-Vis) under pulsed UV light irradiation at $30 \mathrm{~s}$ intervals. We observe a slight decrease in photocurrent with $\mathrm{M} / \mathrm{TiO}_{2}$ catalysts when compared to pure $\mathrm{TiO}_{2}$. This behavior has been reported earlier by other researchers [37-39]. This might be linked to two competing reactions: (1) the increase in the measured current due to excited electrons within the semiconductor upon $\mathrm{UV}$ irradiation and (2) $\mathrm{H}^{+}$reduction due to the presence of the metal which in turn resulted in decreasing the measured current (pumping away the excited electrons). Figure $5 \mathrm{~b}$ shows the photocurrent measured under visible light irradiation and only $\mathrm{Au} / \mathrm{TiO}_{2}$ showed some photocurrent activity (which is about $2 \%$ of that under UV); in line with the marginal catalytic activity measured under visible light only. Thus while Au improves the measured photocurrent under visible light these electrons cannot result 
Fig. 5 Short circuit photocurrents using a two electrode setup under zero bias. Working electrode consisted of the $\mathrm{M} / \mathrm{TiO}_{2}$ photocatalysts coated on ITO/ glass electrodes $\left(4 \mathrm{~cm}^{2}\right.$ area $)$ with Pt as counter electrode. a Under UV light irradiation (300-400 nm: $\left.6.7 \mathrm{~mW} / \mathrm{cm}^{2}\right)$, b under visible light irradiation (420-620 nm: $41.7 \mathrm{~mW} / \mathrm{cm}^{2}$ ), (c) under UV-Vis light irradiation (300-620 nm: $57 \mathrm{~mW} / \mathrm{cm}^{2}$ )
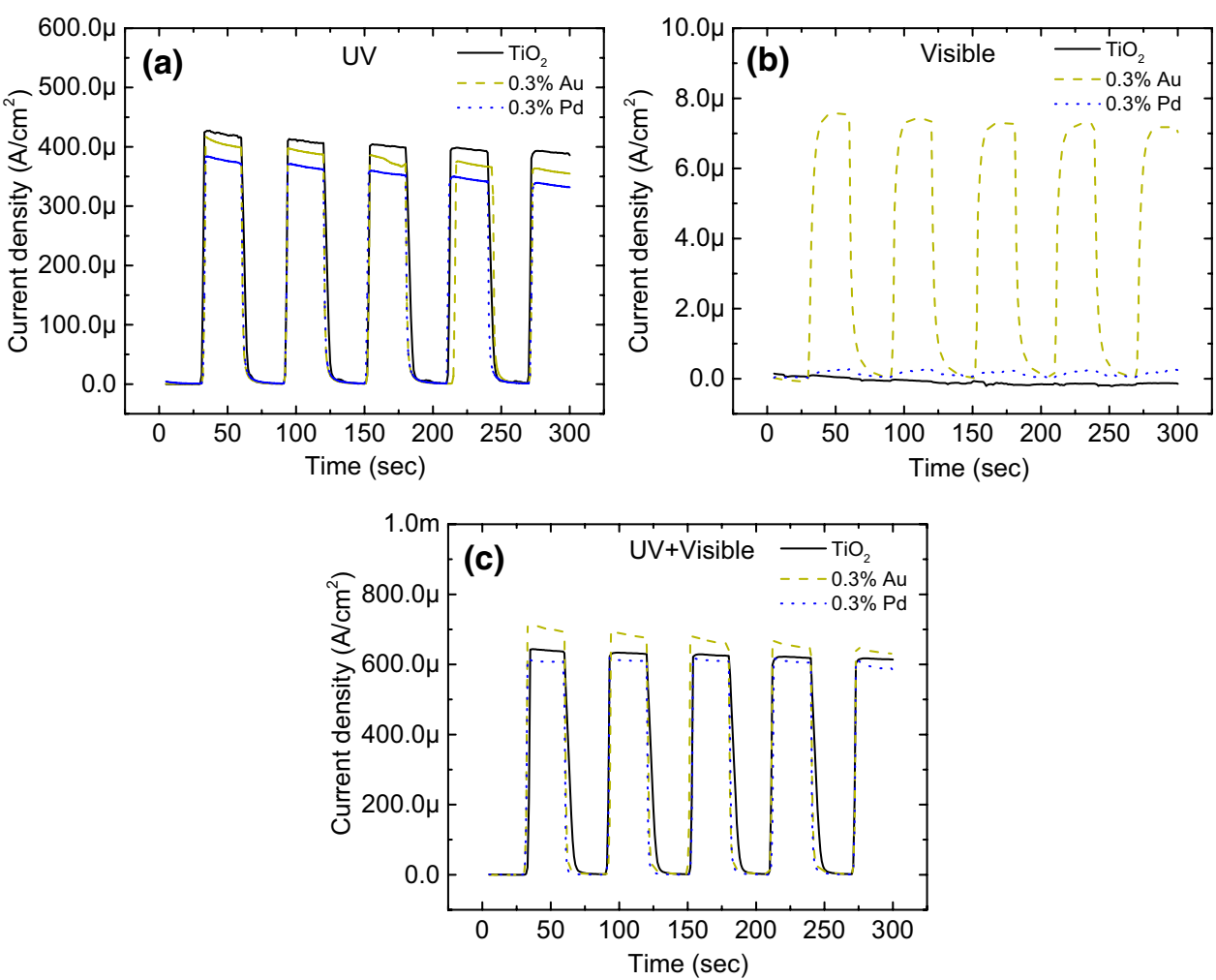

in molecular hydrogen production since the catalytic cycle is not closed; no holes are formed in the $\mathrm{VB}$ of $\mathrm{TiO}_{2}$. In other words, electron injection from the sacrificial agent (glycerol) into the $\mathrm{VB}$ of $\mathrm{TiO}_{2}$ cannot happen unless the $\mathrm{TiO}_{2}$ is photoexcited. The photocurrent response under a combination of UV-Vis light is shown in Fig. 5c. In this case, all catalysts exhibited considerable photocurrent activity yet, $\mathrm{Au} / \mathrm{TiO}_{2}$ showed the highest photocurrent. To summarize this section we observed three behaviors.

(i) Under UV light $\mathrm{TiO}_{2}$ alone had the highest current because of $\mathrm{H}^{+}$reduction in $\mathrm{M} / \mathrm{TiO}_{2}$ catalysts which reduces excited electrons collection in the short-circuit configuration.

(ii) Under visible light $\mathrm{Au} / \mathrm{TiO}_{2}$ was the only responsive catalyst because excited (plasmonic) electrons flows from $\mathrm{Au}$ to the semiconductor but because the VB of $\mathrm{TiO}_{2}$ is fully occupied they cannot contribute into the other half-reaction.

(iii) Under both UV and visible light excitation, $\mathrm{Au} / \mathrm{TiO}_{2}$ had a slightly more current response than $\mathrm{Pd} / \mathrm{TiO}_{2}$ because in this case both electrons due to SPR of $\mathrm{Au}$ and due to $\mathrm{TiO}_{2}$ band gap excitation contribute into the current.
Fig. 6 a Hydrogen production rates $(\mathrm{mol} / \mathrm{g} / \mathrm{min})$ as function of amount of catalyst in $4 \mathrm{~cm}^{2}$ area for different $\mathrm{M} / \mathrm{TiO}_{2}$ photocatalysts under UV light irradiation. b Drop in hydrogen production rates as function of amount of catalyst in $4 \mathrm{~cm}^{2}$ area for different $\mathrm{M} / \mathrm{TiO}_{2}$ photocatalysts under UV-Vis light irradiation
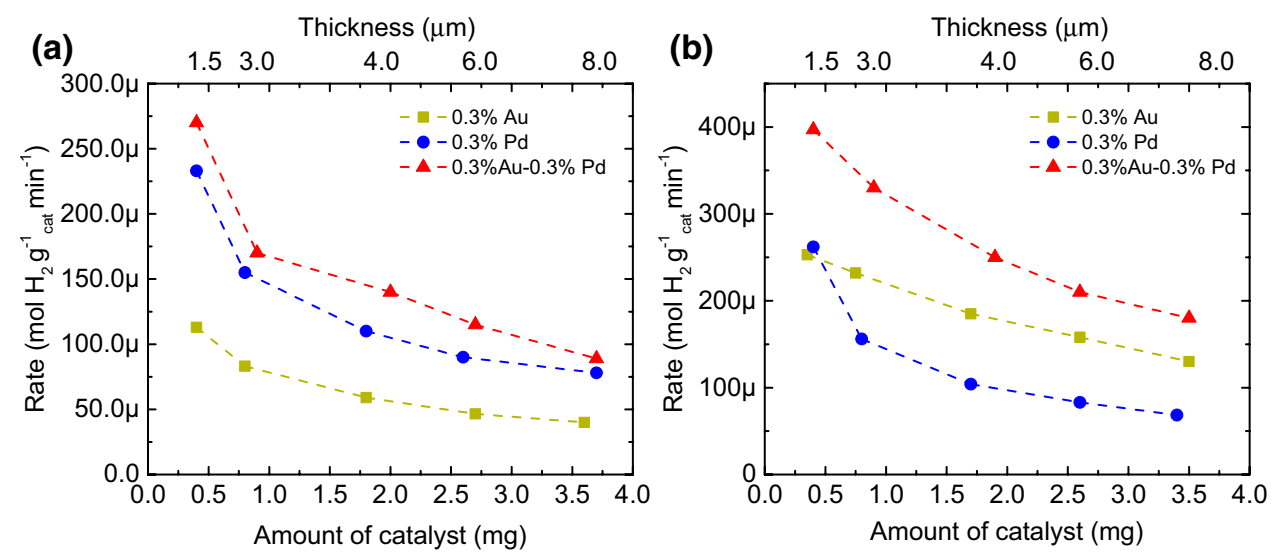
To further probe into the role of $\mathrm{Au}$ in the reaction and knowing that visible light has a longer penetration depth $(\sim 200 \mathrm{~nm}$ at excitation with $350 \mathrm{~nm}$ and increasing to $500 \mathrm{~nm}$ at excitation with $550 \mathrm{~nm}$ for example) than UV light into the semiconductor $\mathrm{TiO}_{2}$, we have increased the thickness of the photo-catalyst coatings until we reached saturation in the amount of $\mathrm{H}_{2}$ produced. Figure 6a shows the $\mathrm{H}_{2}$ production rates $\left(\mathrm{mol} / \mathrm{g}_{\mathrm{Catal}} / \mathrm{min}\right)$ under UV light excitation where we observe a drop in activity as a function of thickness of the coatings (note that the total amount of hydrogen increases). This is expected because with increasing thickness fewer photocatalyst nanoparticles absorb light. Both $\mathrm{Au} / \mathrm{TiO}_{2}, \mathrm{Pd} / \mathrm{TiO}_{2}$ show similar behavior. A similar set of experiments was conducted under UV-Vis light excitation. Figure $6 \mathrm{~b}$ also shows the drop in $\mathrm{H}_{2}$ rates $\left(\mathrm{mol} / \mathrm{g}_{\text {Catal }} /\right.$ min) as a function of thickness of the coatings. Yet, the drop in reaction rates is different for the two metals. The decrease was nearly linear in the case of $\mathrm{Au}$, while it still showed an exponential (or second order polynomial) decay for $\mathrm{Pd}$. Also shown in the figure for further comparisons, the same results for an Au-Pd (0.3 wt\% each); the effect of Au on the reaction rate was still present. These results indicate that one can produce more hydrogen molecules per exposed unit area due to the presence Au metal nanoparticles when using UV-Vis light. The most logical reason would be the effect of light absorption, the Au nanoparticles, absorbing visible light, would be excited in deeper layers because of the difference in light penetration depth (weaker photons penetrates deeper into the semiconductor). To further confirm that there is indeed an enhancement of the reaction rate under UV-Vis when compared to UV alone, Fig. 7 shows an experiment for $\mathrm{Au} / \mathrm{TiO}_{2}$ where the reaction was first conducted under UV-Vis for the first $168 \mathrm{~min}$ then under UV light without

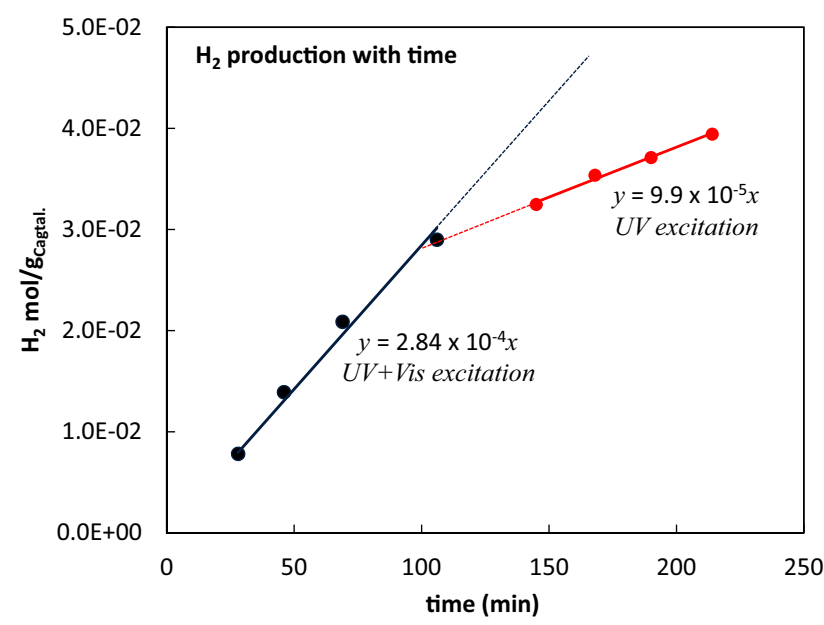

Fig. 7 Photocatalytic reactions of $0.3 \mathrm{wt} \% \mathrm{Au} / \mathrm{TiO}_{2}$ under UVVis then after UV as a function of time. Slide area: $4 \mathrm{~cm}^{2}$, catalyst weight: $0.4 \mathrm{mg}$, total liquid: $20 \mathrm{~mL}$ ( $5 \mathrm{vol} \%$ glycerol) purging the reactor. The initial slope $2.8 \times 10^{-4} \mathrm{~mol} / \mathrm{g}_{\mathrm{Catal}} /$ min decreased to ca. $10^{-4} \mathrm{~mol} / \mathrm{g}_{\mathrm{Catal}} / \mathrm{min}$. One may link this increase to increasing reaction temperature due to visible light effect since the one used is relatively intense (ca. $200 \mathrm{~mW} / \mathrm{cm}^{2}$ in the $400-600 \mathrm{~nm}$ range, which is $3-4$ times higher than that of sun light). Indeed increasing reaction temperature by few degrees can be achieved using visible light at the plasmon absorption threshold of Au nanoparticles (and other plasmonic nanoparticles) but the excitation energy needed for this to have an effect on reaction kinetics would be in the multiples of $\mathrm{W} / \mathrm{cm}^{2}$ (typically conducted by laser light) [40, 41]; far above the one used in this study. This almost three times decrease in the reaction rate is a clear indication for the enhancement of the rate due to $\mathrm{Au}$ particles. No change in the reaction rate is seen when using $\mathrm{Pd} / \mathrm{TiO}_{2}$ instead of $\mathrm{Au} / \mathrm{TiO}_{2}$. The effect of LSPR of $\mathrm{Au}$ on the photocatalytic reactions has been studied by many workers including us in some details elsewhere and in this particular case may be linked to both near field effect or to hot electrons [28, 42-45]. Yet, the important point to take from this study is that these alone are not poised to generate hydrogen in large amounts in the absence of the needed light frequency to excite the semiconductor (in this case UV light for $\mathrm{TiO}_{2}$ ).

\section{Conclusions}

We have investigated the role of plasmonic and non plasmonic metal co-catalysts ( $\mathrm{Au}$ and $\mathrm{Pd}$ ) loaded on $\mathrm{TiO}_{2}$ for photocatalytic hydrogen production from water-glycerol mixtures. We analyzed the activity as a function of metal loading, number of metal atoms to decouple Schottky from plasmonic effects. The catalysts were tested both under UV and visible light. We observed that under UV light the activity of $\mathrm{Pd}$ and $\mathrm{Au}$ metals was similar and noted that the activity is only weakly dependent on their WF. On the other hand under UV-Vis light, the Au metal had larger effect than $\mathrm{Pd}$ due to combined Schottky and plasmonic effects. We also observed that both the semiconductor and plasmonic metal need to be excited to see an enhancement in the hydrogen production due to plasmonics. Furthermore, we found evidences that $\mathrm{Au}$ particles increase light penetration depth; for thick coatings and under UV-Vis light, Au is observed to be $\sim 2 \times$ more active than $\mathrm{Pd}$.

Open Access This article is distributed under the terms of the Creative Commons Attribution 4.0 International License (http://creativecommons.org/licenses/by/4.0/), which permits unrestricted use, distribution, and reproduction in any medium, provided you give appropriate credit to the original author(s) and the source, provide a link to the Creative Commons license, and indicate if changes were made. 


\section{References}

1. Li R, Zhang F, Wang D, Yang J, Li M, Zhu J, Zhou X, Han H, Li C (2013) Spatial separation of photogenerated electrons and holes among $\{010\}$ and $\{110\}$ crystal facets of $\mathrm{BiVO}_{4}$. Nat Commun $4: 1432$

2. Kim JH, Jang J-W, Jo YH, Abdi FF, Lee YH, Van De Krol R, Lee JS (2016) Hetero-type dual photoanodes for unbiased solar water splitting with extended light harvesting. Nat Commun 7:13380

3. Park M, Seo JH, Song H, Nam KM (2016) Enhanced visible light activity of single-crystalline $\mathrm{WO}_{3}$ microplates for photoelectrochemical water oxidation. J Phys Chem C 120:9192-9199

4. Khan MA, Al-Oufi M, Tossef A, Al-Salik Y, Idriss H (2015) On the role of $\mathrm{CoO}$ in $\mathrm{CoO}_{\mathrm{x}} / \mathrm{TiO}_{2}$ for the photocatalytic hydrogen production from water in the presence of glycerol. Catal Struct React 1:192-200

5. Lu AY, Yang X, Tseng CC, Min S, Lin SH, Hsu CL, Li H, Idriss H, Kuo JL, Huang KW (2016) High-sulfur-vacancy amorphous molybdenum sulfide as a high current electrocatalyst in hydrogen evolution. Small 12:5530-5537

6. Majeed I, Nadeem MA, Al-Oufi M, Nadeem MA, Waterhouse G, Badshah A, Metson J, Idriss H (2016) On the role of metal particle size and surface coverage for photo-catalytic hydrogen production: a case study of the Au/CdS system. Appl Catal B 182:266-276

7. Sun Z, Zheng H, Li J, Du P (2015) Extraordinarily efficient photocatalytic hydrogen evolution in water using semiconductor nanorods integrated with crystalline $\mathrm{Ni}_{2} \mathrm{P}$ cocatalysts. Energy Environ Sci 8:2668-2676

8. Kibria MG, Qiao R, Yang W, Boukahil I, Kong X, Chowdhury FA, Trudeau ML, Ji W, Guo H, Himpsel F (2016) Atomic-scale origin of long-term stability and high performance of $\mathrm{p}-\mathrm{GaN}$ nanowire arrays for photocatalytic overall pure water splitting. Adv Mater 28:8388-8397

9. AlOtaibi B, Nguyen H, Zhao S, Kibria M, Fan S, Mi Z (2013) Highly stable photoelectrochemical water splitting and hydrogen generation using a double-band $\mathrm{InGaN} / \mathrm{GaN}$ core/shell nanowire photoanode. Nano Lett 13:4356-4361

10. Ye S, Wang R, Wu M-Z, Yuan Y-P (2015) A review on $\mathrm{gC}_{3} \mathrm{~N}_{4}$ for photocatalytic water splitting and $\mathrm{CO}_{2}$ reduction. Appl Surf Sci 358:15-27

11. Hisatomi T, Kubota J, Domen K (2014) Recent advances in semiconductors for photocatalytic and photoelectrochemical water splitting. Chem Soc Rev 43:7520-7535

12. Khan MA, Nadeem MA, Idriss H (2016) Ferroelectric polarization effect on surface chemistry and photo-catalytic activity: a review. Surf Sci Rep 71:1-31

13. Serpone N, Emeline AV, Ryabchuk VK, Kuznetsov VN, Artem'ev YM, Horikoshi S (2016) Why do hydrogen and oxygen yields from semiconductor-based photocatalyzed water splitting remain disappointingly low? Intrinsic and extrinsic factors impacting surface redox reactions. ACS Energy Lett 1:931-948

14. Nadeem MA, Connelly KA, Idriss $H$ (2012) The photoreaction of $\mathrm{TiO}_{2}$ and $\mathrm{Au} / \mathrm{TiO}_{2}$ single crystal and powder with organic adsorbates. Int J Nanotechnol 9:121-162

15. Schneider J, Matsuoka M, Takeuchi M, Zhang J, Horiuchi Y, Anpo M, Bahnemann DW (2014) Understanding $\mathrm{TiO}_{2}$ Photocatalysis: mechanisms and Materials. Chem Rev 114:9919-9986

16. Nadeem AM, Muir J. M. R., Waterhouse G. W. N., Idriss H (2011) Hydrogen photo-production from ethanol on TiO: a surface science and catalysis study. Proc SPIE 8109:81090K-81090K-9

17. Jovic V, Al-Azri Z. H. N., Chen W-T, Sun-Waterhouse D, Idriss $\mathrm{H}$, Waterhouse GIN (2013) Photocatalytic $\mathrm{H}_{2}$ production from ethanol-water mixtures over $\mathrm{Pt} / \mathrm{TiO}_{2}$ and $\mathrm{Au} / \mathrm{TiO}_{2}$ photocatalysts: a comparative study. Top Catal 56:1139-1151
18. Murdoch M, Waterhouse GIN, Nadeem MA, Metson JB, Keane MA, Howe RF Llorca J, Idriss H (2011) The effect of gold loading and particle size on photocatalytic hydrogen production from ethanol over $\mathrm{Au} / \mathrm{TiO}_{2}$ nanoparticles. Nat Chem 3:489-492

19. Al-Azri ZHN, Chen W-T, Chan A, Jovic V, Ina T, Idriss H, Waterhouse GIN (2015) The roles of metal co-catalysts and reaction media in photocatalytic hydrogen production: performance evaluation of $\mathrm{M} / \mathrm{TiO}_{2}$ photocatalysts $(\mathrm{M}=\mathrm{Pd}, \mathrm{Pt}, \mathrm{Au})$ in different alcohol-water mixtures. J Catal 329:355-367

20. Nadeem AM, Waterhouse G. I. N., Metson JB, Idriss H (2010) Hydrogen production by photoreaction of ethanol over $\mathrm{Au} / \mathrm{TiO}_{2}$ anatase: the effect of $\mathrm{TiO} 2$ particle size. SPIE Solar Energy Technol. doi: $10.1117 / 12.861471$

21. Iwata K, Takaya T, Hamaguchi H.-o., Yamakata A, Ishibashi T.-A., Onishi H, Kuroda H (2004) Carrier dynamics in $\mathrm{TiO}_{2}$ and $\mathrm{Pt} / \mathrm{TiO}_{2}$ powders observed by femtosecond time-resolved nearinfrared spectroscopy at a spectral region of $0.9-1.5 \mu \mathrm{m}$ with the direct absorption method. J Phys Chem B 108:20233-20239

22. Furube A, Asahi T, Masuhara H, Yamashita H, Anpo M (2001) Direct observation of a picosecond charge separation process in photoexcited platinum-loaded $\mathrm{TiO} 2$ particles by femtosecond diffuse reflectance spectroscopy. Chem Phys Lett 336:424-430

23. Bamwenda GR, Tsubota S, Nakamura T, Haruta M (1995) Photoassisted hydrogen production from a water-ethanol solution: a comparison of activities of $\mathrm{Au} \mathrm{TiO}_{2}$ and $\mathrm{Pt} \mathrm{TiO}_{2}$. J Photochem Photobiol A 89:177-189

24. Yang YZ, Chang CH, Idriss H (2006) Photo-catalytic production of hydrogen form ethanol over $\mathrm{M} / \mathrm{TiO}_{2}$ catalysts $(\mathrm{M}=\mathrm{Pd}$, Pt or Rh). Appl Catal B 67:217-222

25. Cushing SK, Wu N (2016) Progress and perspectives of plasmonenhanced solar energy conversion. J Phys Chem Let 7:666-675

26. Xuming Z, Yu Lim C, Ru-Shi L, Din Ping T (2013) Plasmonic photocatalysis. Rep Prog Phys 76:046401

27. Hou W, Cronin SB (2013) A review of surface plasmon resonance-enhanced photocatalysis. Adv Funct Mater 23:1612-1619

28. Gomes Silva C, Juárez R, Marino T, Molinari R, García H (2011) Influence of excitation wavelength (UV or visible light) on the photocatalytic activity of titania containing gold nanoparticles for the generation of hydrogen or oxygen from water. J Am Chem Soc 133:595-602

29. Rosseler O, Shankar MV, Du M. K.-L., Schmidlin L, Keller N, Keller V (2010) Solar light photocatalytic hydrogen production from water over $\mathrm{Pt}$ and $\mathrm{Au} / \mathrm{TiO}_{2}$ (anatase/rutile) photocatalysts: Influence of noble metal and porogen promotion. J Catal 269:179-190

30. Khan MA, Sinatra L, Oufi M, Bakr OM, Idriss H (2017) Evidence of plasmonic induced photocatalytic hydrogen production on $\mathrm{Pd} /$ $\mathrm{TiO}_{2}$ upon deposition on thin films of gold. Catal Lett 147:1-10

31. Mulvaney P (1996) Surface plasmon spectroscopy of nanosized metal particles. Langmuir 12:788-800

32. Wood A, Giersig M, Mulvaney P (2001) Fermi level equilibration in quantum dot-metal nanojunctions. J Phys Chem B 105:8810-8815

33. Huang S, Yu Y, Yan Y, Yuan J, Yin S, Cao Y (2016) Enhanced photocatalytic activity of $\mathrm{TiO}_{2}$ activated by doping $\mathrm{Zr}$ and modifying Pd. RSC Adv 6:29950-29957

34. Nadeem MA, Majeed I, Waterhouse GIN, Idriss H (2015) Study of ethanol reactions on $\mathrm{H}_{2}$ reduced $\mathrm{Au} / \mathrm{TiO}_{2}$ anatase and rutile: effect of metal loading on reaction selectivity. Catal Struct React $1: 61-70$

35. Wahab AK, Idriss H (2017) Kinetics of ethylene glycol photoreactions at different partial pressures of Oxygen (in preparation)

36. Zhu G, Su F, Lv T, Pan L, Sun Z (2010) Au nanoparticles as interfacial layer for CdS quantum dot-sensitized solar cells. Nanoscale Res Lett 5:1749 
37. Zare M, Mortezaali A, Shafiekhani A (2016) Photoelectrochemical determination of shallow and deep trap states of platinumdecorated $\mathrm{TiO}_{2}$ nanotube arrays for photocatalytic applications. J Phys Chem C 120:9017-9027

38. Lakshminarasimhan N, Bokare AD, Choi W (2012) Effect of agglomerated state in mesoporous $\mathrm{TiO}_{2}$ on the morphology of photodeposited pt and photocatalytic activity. J Phys Chem C 116:17531-17539

39. Chen W, Lu Y, Dong W, Chen Z, Shen M (2014) Plasmon mediated visible light photocurrent and photoelectrochemical hydrogen generation using Au nanoparticles/ $/ \mathrm{TiO}_{2}$ electrode. Mater Res Bull 50:31-35

40. Baffou G, Quidant R, Girard C (2009) Heat generation in plasmonic nanostructures: Influence of morphology. Appl Phys Lett 94:153109
41. Roper DK, Ahn W, Hoepfner M (2007) Microscale heat transfer transduced by surface plasmon resonant gold nanoparticles. J Phys Chem C 111:3636-3641

42. Liu Z, Hou W, Pavaskar P, Aykol M, Cronin SB (2011) Plasmon resonant enhancement of photocatalytic water splitting under visible illumination. Nano Lett 11:1111-1116

43. Tian Y, Tatsuma T (2005) Mechanisms and applications of plasmon-induced charge separation at $\mathrm{TiO}_{2}$ films loaded with gold nanoparticles. J Am Chem Soc 127:7632-7637

44. Tian Y, Tatsuma T (2004) Plasmon-induced photo-electrochemistry at metal nanoparticles supported on nanoporous $\mathrm{TiO}_{2}$. Chem Commun 16:1810-1811

45. Amrollahi R, Hamdy MS, Mul G (2014) Understanding promotion of photocatalytic activity of $\mathrm{TiO}_{2}$ by Au nanoparticles. J Catal 319:194-199 